Died, lately, George Gilbert Currey, M.D. senior physician to St. Thomas's Hospital. We nnderstand that Dr. Currey had for some time laboured under an affection of the heart, and that the symptoms of his last illness were referrible to the chest. He had been very lately married.

\title{
METEOROLOGICAL JOURNAL.
}

By Messrs. William Harris and Co. 50, Holborn, London.

From November 20, 1822, to December 19, 1822.

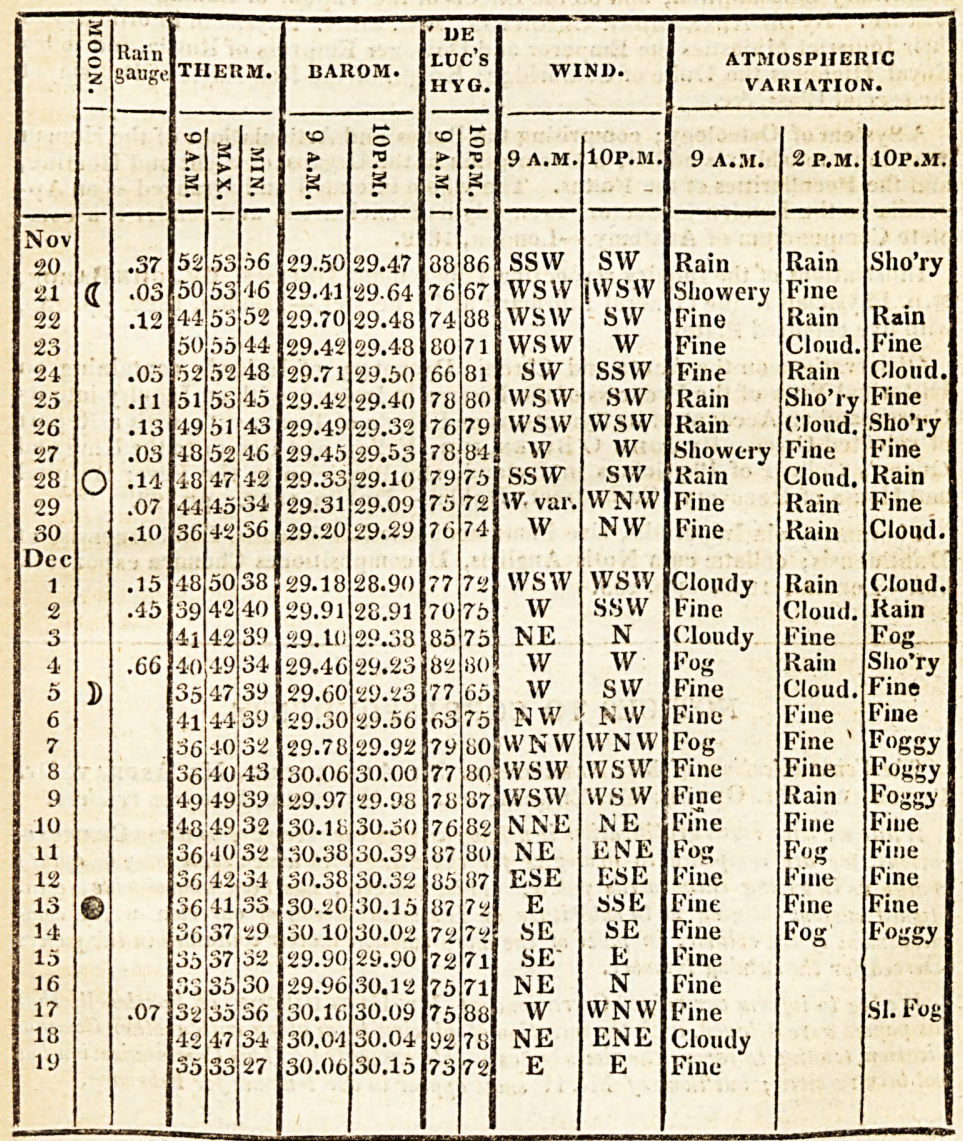

The quantity of rain that has fallen in the month of November, was 3 inches and 15.100 ths. 